\title{
Original
}

\section{Calcium, Phosphorus and Oxygen Around Implant at Early Osseointegration in Hyperlipidemic Rats}

\author{
Qibo Liu ${ }^{1,2) *}$, Zhifeng Wang ${ }^{1,3)} *$ Xiaofei Dong ${ }^{4)}$, Hui Wang ${ }^{5)}$ and Jing Lan $^{1,2)}$ \\ 1) Shandong Provincial Key Laboratory of Oral Tissue Regeneration, School of Stomatology, Shandong University, Jinan, Shandong, China \\ 2) Department of Prosthodontics, School of Stomotology, Shandong University, Jinan, Shandong, China \\ ${ }^{3)}$ Department of Pediatric Dentistry, School of Stomotology, Shandong University, Jinan, Shandong, China \\ 4) The State Key Laboratory Breeding Base of Basic Science of Stomatology (Hubei-MOST) \& Key Laboratory of Oral Biomedicine Ministry of Ed- \\ ucation, School \& Hospital of Stomatology, Wuhan University, Wuhan, Hubei, China \\ 5) Department of Dental Implantology, Affiliated Stomological Hospital of Suzhou University, Suzhou, Jiangsu, China \\ (Accepted for publication, December 22, 2018)
}

\begin{abstract}
The study was to observe dental implant osseointegration at early stage and analysis the influencement of the ratio of calcium and phosphorus variation on osseointegration in hyperlipidemic rats. Wistar rats were randomly divided into control group with normal diet and experimental group with high fat diet. 8 weeks later, serum lipid levels was detected and titanium implants were placed into bilateral femurs. At day1, 3, 5 after implant, rats were sacrificed and $5 \mathrm{~mm}$ bone with implants was obtained. hard tissue slices and methylene blue-acid fuchsin staining were performed to observe the interface of bone-implant. And energy disperse X-ray spectrometer (EDS) was used to measure the percentage of oxygen and the ratio of calcium and phosphorus. All rats in experimental group were successfully induced into hyperlipidemic status. Histological results revealed less osteoblasts and trabecular bone, but more osteoclasts and trabecular space in experimental group than those in control group. Higher content of oxygen and lower ration of calcium and phosphorus were also observed in experimental group than those in control group $(\mathrm{P}<0.05)$. Hyperlipidemia could hinder implant osseointegration at early stage after implantation. This inhibition might be closely related to higher content of oxygen and lower ratio of calcium and phosphorus.
\end{abstract}

Key Words: Bone healing, Hyperlipidemia, Implant osseointegration, Oxygen, Ratio of calcium and phosphorus

\section{Introduction}

Hyperlipidemia is characterized with elevated lipids in bloodstream, which is caused by atherosclerosis or high-fat (HF) diet. Hyperlipidemia is closely related to osteoporosis, which usually involves alveolar bone ${ }^{1)}$. And mice with HF diet demonstrate significant increased implant failure, decreased bone formation and compromising strength of implant-bone interface ${ }^{2)}$. In recent years, the morbidity of hyperlipidemia is increasing. In America, $12.1 \%$ of adults had high total cholesterol (TC) and $18.5 \%$ with low high-density lipoprotein (LDL) cholesterol during 2011-2014 ${ }^{3)}$.

With the survive rate of dental implant is high, it becomes common prosthetics in the world. The successful osseointegration is determined the long-term survive rate. The studies about the influencement of hyperlipidemia on implant osseointegration is still at an initial stage. Some studies have indicated that hyperlipidemia inhibits osteoblastogenesis and bone metabolism through hindering alkaline phosphatase activity and mineralization ${ }^{4,5}$, which were markers of osteoblast differentiation. Hyperlipidemia also impaired bone regeneration and mechanical strength $^{6,7)}$

*Qibo Liu and Zhifeng Wang are co-first authors.

Correspondence to: Dr. Jing Lan, Shandong Provincial Key Laboratory of Oral Tissue Regeneration, Department of Prosthodontics, School of Stomatology, Shandong University, No.44-1 Wenhua Road West, Jinan, China;

Fax: 86-531-88382923; Email: lanjing@sdu.edu.cn
Oxygen $(\mathrm{O})$ is necessary in cell metabolism and bone repair by regulating proliferation and differentiation of bone marrow stem cells (BM$\mathrm{SCs})$, chondrocytes and osteoblasts ${ }^{8-11)}$. O participates oxidation-reduction reaction to produce reactive oxygen species (ROS). High lipid level could increase oxidative stress by overproduction of $\operatorname{ROS}^{12)}$ that bone healing process between the implant-bone interface was suppressed ${ }^{13-15)}$. Except $\mathrm{O}$, calcium $(\mathrm{Ca})$ and phosphorus $(\mathrm{P})$ are also important components in bone mineralization and bone formation ${ }^{16-19)}$. Ca has been proved to be crucial in implant osseointegration, involving platelet adhesion, orientation and conformation of proteins on the interface ${ }^{20,21)}$. Low concentration of $\mathrm{P}$ is released from bone, which simultaneously lead to the release of $\mathrm{Ca}$ because of an unfavorable ratio of $\mathrm{Ca}$ to $\mathrm{P}(\mathrm{Ca} /$ $\mathrm{P})^{22)}$. Interaction between $\mathrm{Ca}$ and $\mathrm{P}$ could affect bone metabolism and development $\mathrm{t}^{23,24)}$. The $\mathrm{Ca} / \mathrm{P}$ was positively related to bone density, strength and quality ${ }^{25)}$. Maintaining an adequate $\mathrm{Ca}$ and $\mathrm{P}$ with appropriate ratio is of crucial importance for implant-bone interface stability and good osseointegration. But the effect of hyperlipidemia on $\mathrm{O}, \mathrm{Ca}$ and $\mathrm{P}$ is still unknown.

The poor implant osseointegration at implant-bone interface at the early stage after implantation resulted in the majority of dental implants failure $^{26,27)}$. In this study, we observed implant osseointegration at implant-bone interface of hyperlipidemic rats from histological slices. Meanwhile, $\mathrm{O}, \mathrm{Ca}$ and $\mathrm{P}$ in tissue were also assayed using EDS. 

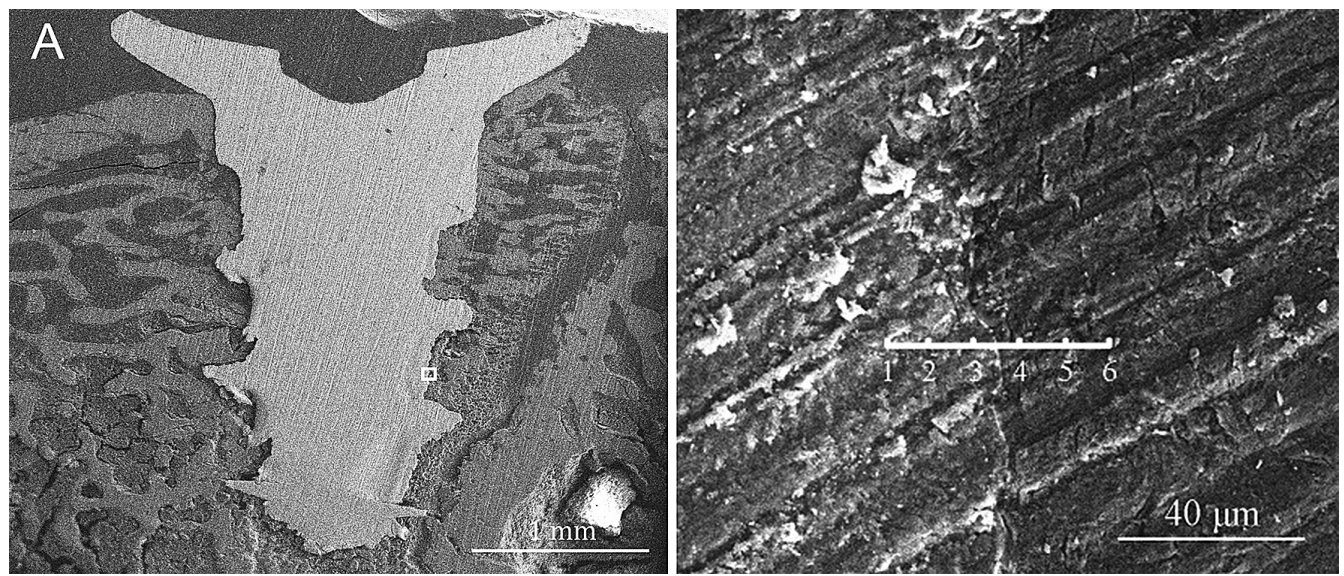

Figure 1. Six microzones analyzed by EDS. (A) The selected area is in the middle part of the implant 1/3. (B) A line, perpendicular to the long axis of implants, was drawn and then " $1 \sim 6$ " six points at $10 \mu \mathrm{m}$ intervals along the implant in this line was chosen, which was also called six microzones. The midpoints of " 3 " and " 4 " were around the edge of implants.

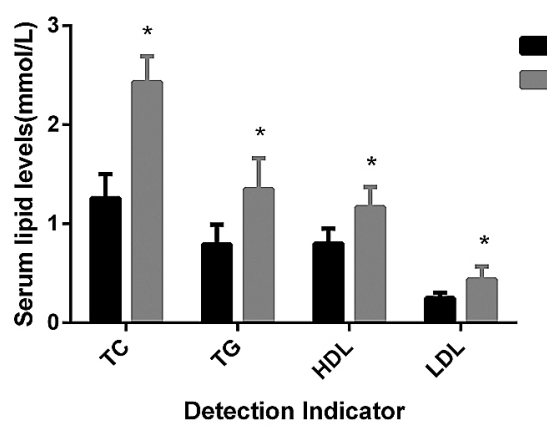

Figure 2. The serum levels of two groups. The rats in experimental group whose serum levels of TC were about 2 times more than rats in control group and levels of TG and LDL were significantly higher than those of control group were defined as successful hyperlipidemic rats.

\section{Materials and Methods}

The study was approved by the ethics committee of Shandong University Dental Hospital, and informed consents were obtained (protocol number GD201615).

\section{Animals}

36 adult male Wistar rats were obtained from Shandong University Experimental Animal Center (Ji'nan, China). All experimental protocols were guided and approved by Institutional Animal Care and Use Committee of School of Stomatology of Shandong University (Ji'nan, China). The rats were randomly devided into control group fed with normal diet and experimental group with HF diet during whole experiment. HF diet was purchased from Beijing Ke'aoxieli Co., Ltd (Beijing, China).

8 weeks later, endocanthion vein blood specimens were collected to monitor serum TC, Triglyceride (TG), high-density lipoprotein (HDL) and LDL.

\section{Implantation and samples preparation}

All rats were anesthetized with chloral hydrate $(0.3 \mathrm{ml} / 100 \mathrm{~g})$. After regular skin preparation and disinfection, a $1 \mathrm{~cm}$ vertical incision was made near the epiphyseal of femur and blunt dissection of femoral rectus and femoral muscles to fully expose bone. The implant hole was prepared by $1.2 \mathrm{~mm}$ pilot drill, which rotated at 800 revolutions per minute and cooled with saline. Titanium (Ti) implants (Shuangyang ${ }^{\circledR}$
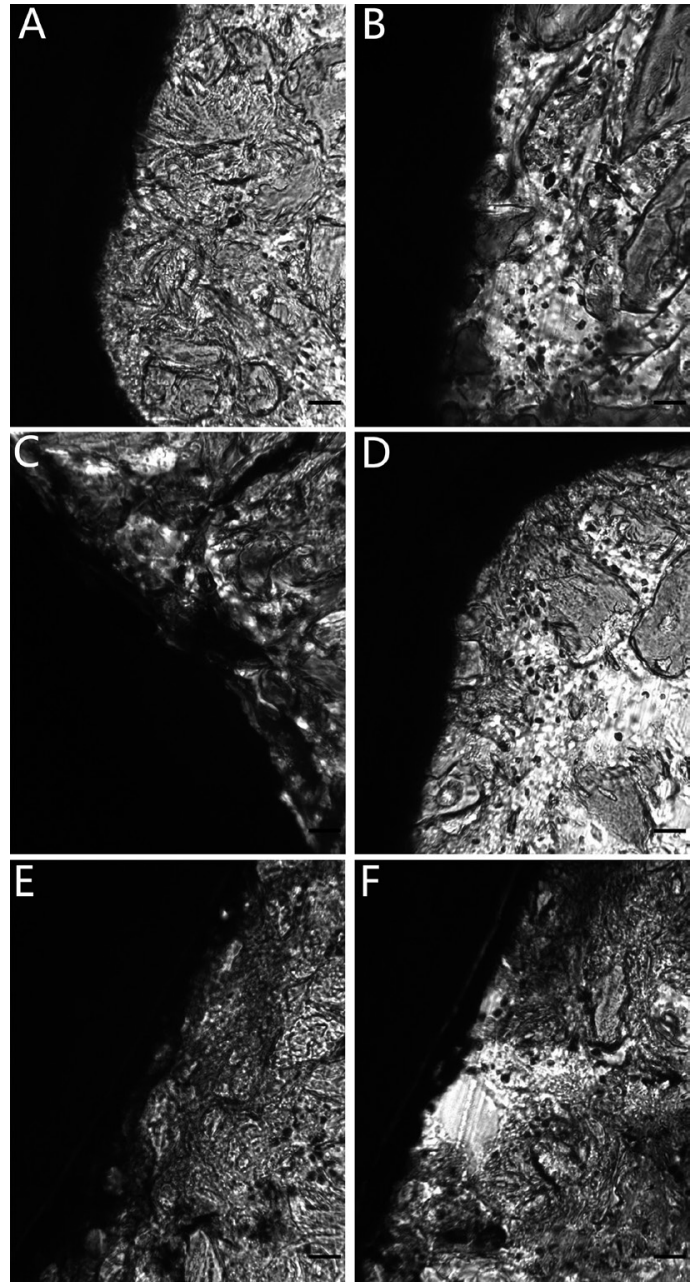

Figure 3. Hard tissue slices and staining. The red dying area was trabecular bone, the dark blue area was osteoblasts and osteoclasts, the black area was the implant, andthe blue violet area was collagen fibers. (A) Control group at day 1 ( $\times 400$ fold). (B) Experimental group at day 1 ( $\times 400$ fold). (C) Control group at day $3(\times 400$ fold $)$. (D) Experimental group at day $3(\times 400$ fold). (E) Control group at day 5 ( $\times 400$ fold). (F) Experimental group at day 5 ( $\times 400$ fold). It can be seen that the trabecular bone (red area) of the experimental group arranged disorder especially at day 5 ; while the bluestained area around the implant was more heavy, meaning that the collagen content was higher. (Methylene blue staining, Bar $=20 \mu \mathrm{m}$ ). 
Qibo Liu et al.: Ca, P and O Around Implant at Early Osseointegration

Table 1. The serum TC, TG, HDL and LDL of two groups

\begin{tabular}{lllll}
\hline & TC & TG & HDL & LDL \\
\hline Control group & $1.26 \pm 0.24$ & $0.79 \pm 0.20$ & $0.80 \pm 0.15$ & $0.25 \pm 0.05$ \\
Experimental group & $2.43 \pm 0.26^{*}$ & $1.35 \pm 0.31^{*}$ & $1.17 \pm 0.20^{*}$ & $0.44 \pm 0.13^{*}$ \\
\hline & & & & $($ mean \pm SD mmol/1, n=18)
\end{tabular}

The rats in experimental group whose serum levels of TC were about 2 times more than rats in control group and levels of TG and LDL were significantly higher than those of control group were defined as successful hyperlipidemic rats.

*Significant difference between experimental and control group $(\mathrm{P}<0.05)$.

Table 2. The percentage of $\mathrm{O}$ at day $1,3,5$ after implantation

\begin{tabular}{ccccccc}
\hline microzone & C1d & E1d & C3d & E3d & C5d & E5d \\
\hline 4 & $72.76 \pm 2.58$ & $79.29 \pm 3.11^{*}$ & $72.33 \pm 2.71$ & $78.93 \pm 3.07^{*}$ & $72.17 \pm 3.09$ & $78.73 \pm 2.61^{*}$ \\
5 & $63.01 \pm 2.59$ & $69.73 \pm 3.22^{*}$ & $63.09 \pm 2.56$ & $69.81 \pm 3.28^{*}$ & $63.14 \pm 2.64$ & $69.92 \pm 3.12^{*}$ \\
6 & $61.30 \pm 2.51$ & $67.80 \pm 3.16^{*}$ & $61.46 \pm 2.83$ & $68.36 \pm 3.19^{*}$ & $62.04 \pm 2.82$ & $68.66 \pm 3.00^{*}$ \\
\hline
\end{tabular}

"C" means control group, "E" experimental group. C1d indicates the control group 1 day after implantation, E3d indicates the experimental group 3 days after implantation, and so on.

$*$ :Significant differences between experimental and control group at the same time $(\mathrm{P}<0.05)$.

Table 3. The ratio of $\mathrm{Ca} / \mathrm{P}$ at day $1,3,5$ after implantation

\begin{tabular}{ccccccc}
\hline microzone & C1d & E1d & C3d & E3d & C5d & E5d \\
\hline 4 & $1.20 \pm 0.09$ & $1.02 \pm 0.06^{*}$ & $1.29 \pm 0.10$ & $1.09 \pm 0.07^{*}$ & $1.38 \pm 0.11$ & $1.17 \pm 0.07^{*}$ \\
5 & $1.57 \pm 0.14$ & $1.30 \pm 0.08^{*}$ & $1.51 \pm 0.14$ & $1.26 \pm 0.06^{*}$ & $1.48 \pm 0.12$ & $1.23 \pm 0.09^{*}$ \\
6 & $1.65 \pm 0.12$ & $1.40 \pm 0.09^{*}$ & $1.60 \pm 0.13$ & $1.34 \pm 0.09^{*}$ & $1.56 \pm 0.13$ & $1.31 \pm 0.08^{*}$ \\
\hline
\end{tabular}

"C" means control group, "E" experimental group. C1d indicates the control group 1 day after implantation, E3d indicates the experimental group 3 days after implantation, and so on.

*:Significant differences between experimental and control group at the same day $(\mathrm{P}<0.05)$.

A

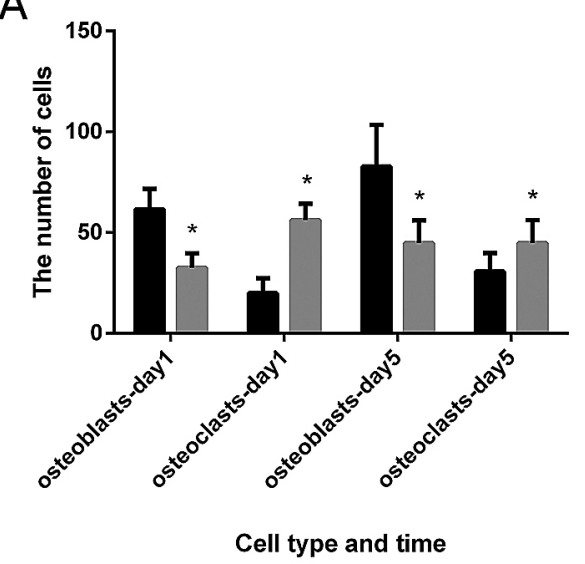

B

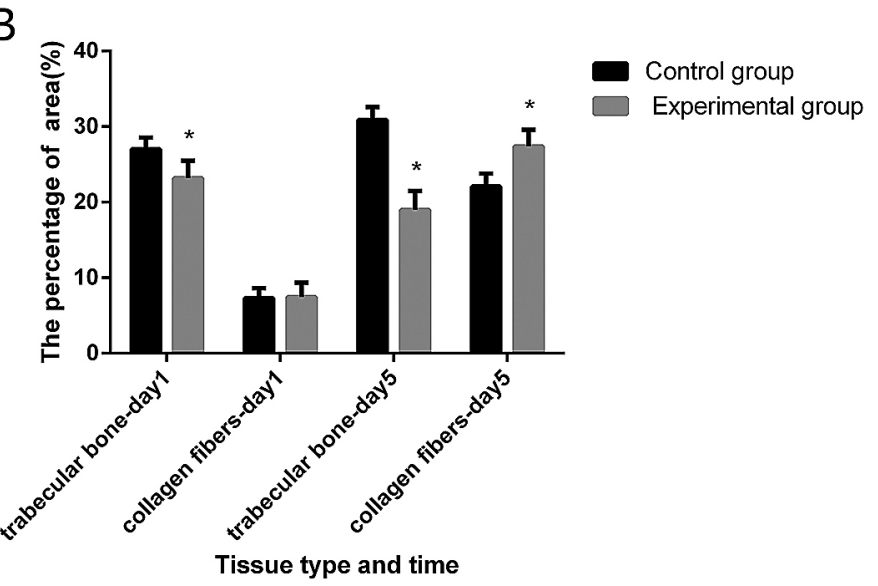

Figure 4. Differences between osteoblasts, osteoclasts, trabeculae and collagen fibers at day 1, 5 after implantation. Quantitative analysis of slices, there were more trabecular bone (B) and osteoblasts (A), less osteoclasts (A) and collagen fibers (B) in control group than those in experimental group at day 1,5 after implantation. $* \mathrm{P}<0.05$.

self-tapping screw, $1.5 \mathrm{~mm}$ wide and $2.5 \mathrm{~mm}$ long, Zhangjiagang city, China) were placed into bilateral femurs distal to epiphyseal. Mucosa and muscles were sutured with 4-0 thread and skin with 5-0. $200000 \mathrm{u}$ Cefazolin sodium was administrated in 3 days after surgery.

At day 1, 3, 5 after implantation, the rats from each group were sacrificed by overdosed chloral hydrate. $5 \mathrm{~mm}$ bones around implants were dissected and fixed in $4 \%$ paraformaldehyde, dehydrated in ascending series of ethanol and embedded with resin.

\section{Hard tissue slices and staining}

The samples were cut and grinded into $30 \mu \mathrm{m}$ thick sections
(E400CS, EXAKT Vertriebs Gmbh, Germany), then methylene blue staining was performed. Inverted microscopy was used to observe and photograph the interface of implant-bone. Image-Pro Plus software was used to analyze the area of trabecular bone and the number of osteoblasts in the original photograph at day 1, 5 after implantation and made a histogram.

\section{Micro-composition analysis}

Other samples of each group were used to measure concentrations of $\mathrm{O}, \mathrm{Ca}$ and $\mathrm{P}$ at six microzones, and calculate percentage and ratio with energy disperse X-ray spectrometer (EDS). Six microzones were 

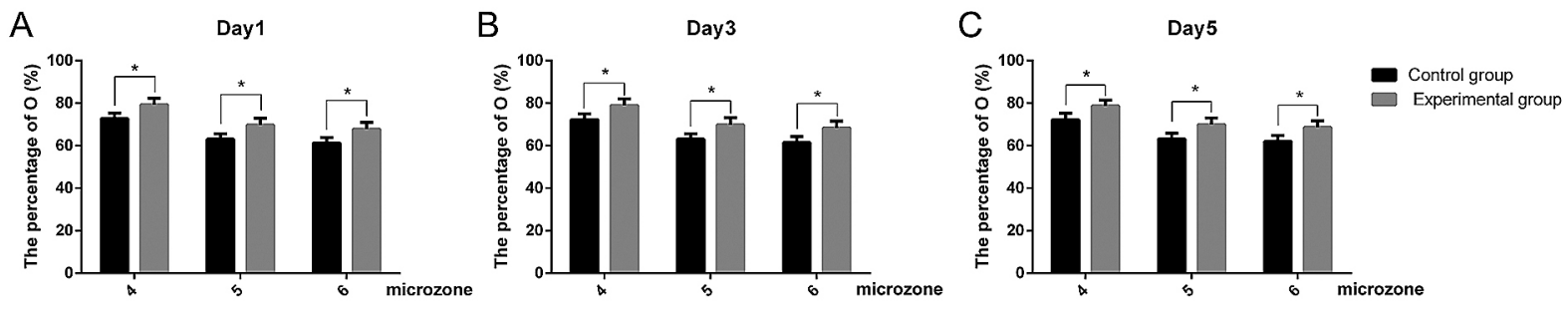

Figure 5. The percentage of $\mathrm{O}$ at day 1,3,5 after implantation. In both groups, the percentage of $\mathrm{O}$ increased a little with time at microzone 5 and 6. Percentage of $\mathrm{O}$ in experimental group was significantly higher than that in control group at microzone 4,5 , and $6\left({ }^{*} \mathrm{P}<0.05\right)$.
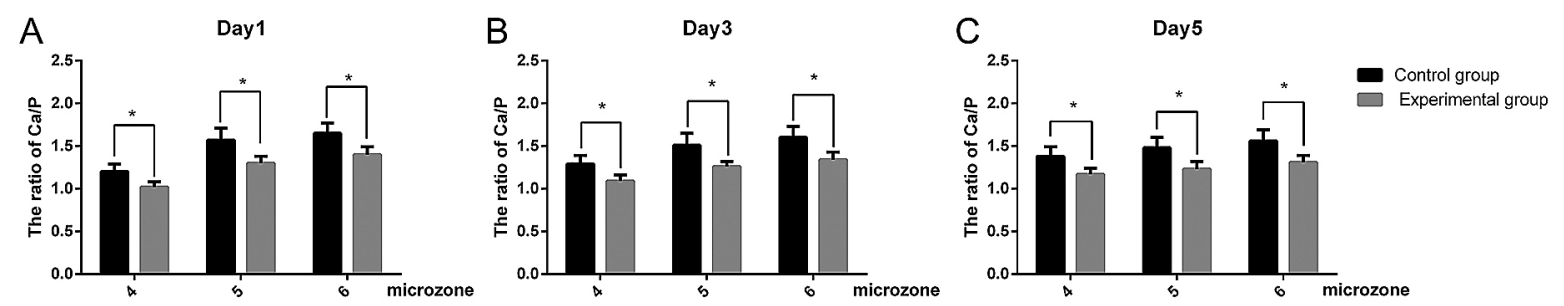

Figure 6. The ratio of $\mathrm{Ca} / \mathrm{P}$ at day $1,3,5$ after implantation. $\mathrm{Ca} / \mathrm{P}$ increased slightly from day 1 to day 5 in both groups at microzone 4 . Ca/P in experimental group was significantly lower than that in control group at microzone 4,5 , and $6\left({ }^{*} \mathrm{P}<0.05\right)$.

marked " $1 \sim 6$ " at $10 \mu \mathrm{m}$ intervals and perpendicular to the medium $1 / 3$ of implants (Fig. 1). "3" and "4" were around the edge of implant.

\section{Statistical analysis}

Data were expressed as mean \pm standard deviation (SD) and analyzed by SPSS software 13.0. Comparisons were analyzed with One-way ANOVA and t-test. $\mathrm{P}<0.05$ was considered statistically significant difference.

\section{Results}

\section{Establishment of hyperlipidemic rats}

TC level in experimental group was about twofold than that in control group $(P<0.05)$, and also TG, HDL and LDL levels were significant higher than those of control group $(P<0.05)$ (Table 1, Fig. 2). All rats in experimental group were successfully induced to hyperlipidemic rats.

\section{Analysis of hard tissue slices}

At day 1, 3 and 5 after implantation, there were crescent-shaped trabecular bone, bone remodeling caused by osteoclast phagocytosis, and gradually increased osteoblasts, osteoclasts and collagen fibers. There is a large amount of osteoclasts distribution, with three or more nuclei in control group (Fig. 3A). In experimental group at day 1, 3, 5 (Fig. 4B, D and F), trabecular bone arranged disorder, and collagen fibers were less around the implant.

Through the quantitative analysis of the slices, there were more trabecular bone (Fig. 4B) and osteoblasts (Fig. 4A), less osteoclasts (Fig. 4A) and collagen fibers (Fig. 4B) in control group than those in experimental group at day 1, 5 after implantation. It can be seen that there is a statistically significant difference between the control group and the experimental group $(* \mathrm{P}<0.05)$.

\section{Micro-composition ananlysis}

In both groups, the percentage of $\mathrm{O}$ increased a little with time at microzone 5 and 6, but decreased at microzone $4(P>0.05)$ (Table 2, Fig. $5)$. Percentage of $O$ in experimental group was significantly higher than that in control group at microzone 4,5 , and $6(P<0.05)$.
$\mathrm{Ca} / \mathrm{P}$ increased slightly from day 1 to day 5 in both groups at microzone 4, but decreased at microzone 5 and $6(P>0.05)$ (Table 3, Fig. 6). $\mathrm{Ca} / \mathrm{P}$ in experimental group was significantly lower than that in control group at microzone 4,5 , and $6(P<0.05)$.

$\mathrm{Ca}, \mathrm{P}$ and $\mathrm{O}$ could not be detected in microzone 1, 2 and 3 .

\section{Discussion}

In this study, we tested the influences of hyperlipidemia on dental implants osteointegration historically in rats at early stages (1st, 3rd, 5th day post-surgery). In our results, osseointegration at early stage was hindered in hyperlipidemic rats and this inhibition might be closely related to higher content of oxygen and lower ratio of calcium and phosphorus than normal rats.

Osteoblasts, which play a key role in osseointegration process, secrete bone matrix with type I collagen as its main component. The deposition of calcium and phosphorus on collagen fibers forms hydroxyapatite to mineralize bone matrix. Osteoblasts are surrounded by newly forming tissue to become bone cells, which in turn produce new bone tissue $^{28)}$. Ca and $\mathrm{P}$ ions around the implant produce an initiating stimulation for osteoblasts resulting in an increasing of the amount of synthetic collagen and ultimately promotes the formation of new bone ${ }^{29)}$. In this study, we found that although the number of osteoblasts and trabecular bone around the two groups increased with time, the composition of bone cells and trabecular bone was less in hyperlipidemia group. There were more osteoclasts and trabecular space than the control group.

HF diet could induce the changes of bone morphological and mechanical properties, such as bone density and content of bone mineral, and affect implant osseointegration ${ }^{2}$. The osseointegration is similar to bone fracture healing. During fracture healing, osteoblasts deposit collagenous matrix. The first day after implantation, mesenchymal cells, pre-osteoblasts and osteoblasts adhered to implant surface and began to produce collagen fibrils, but in the coming days, osteoblasts began to deposit collagen matrix directly on the early formed cement line/lamina limitans layer described on the implant surface ${ }^{30}$. Hyperlipidemia disrupted collagen processing as well as orientation, causing loss of local alignment, which might reduce mechanical integrity and quality of bone 
Qibo Liu et al.: Ca, P and O Around Implant at Early Osseointegration

and impair bone healing ${ }^{31}$.

Epidemiological data showed that HF diet could increase lipoprotein levels and their oxidative products ${ }^{32}$, enhancing oxidative stress ${ }^{12}$. Intracellular oxidative stress was the initial factor for changing of bone metabolism ${ }^{31)}$. Oxidative stress not only led to inhibition of osteogenic signaling pathway, but also decreased formation of mature osteoblasts and expression of molecular markers of bone remodeling ${ }^{33-35)}$. Serum lipid levels had an negative correlation with the bone mineral content, bone mineral density and mass ${ }^{36}$. It was confirmed that oxidative stress induced by ROS at implant-bone interface greatly reduced cells growth onto the implant surface and biological functions of osteoblasts, which would hinder bone repair at early ${ }^{13,15)}$ and later stage, even lead to implant failure ${ }^{14,37)}$. Higher content of $\mathrm{O}$ in experimental group induced overproduction of ROS, which decreased osteoblasts and new bone formation in hyperlipidemia.

$\mathrm{Ca}$ had principal roles at almost every stage of bone repair process: from the formation of the provisional matrix to mineralization and bone remodeling ${ }^{38)}$. Studies in vitro showed that increased concentrations of $\mathrm{Ca}$ and $\mathrm{P}$ ions in the medium contributed to proliferation and differentiation of pre-osteoblasts and MSCs to osteoblasts, leading to new bone formation ${ }^{39-41)}$. Ti implant surfaces modified with $\mathrm{Ca}$ ions stimulated osteoblasts attachment, proliferation and differentiation, and improved implant osseointegration ${ }^{42}$. In addition, $\mathrm{Ca}$ and $\mathrm{P}$ ions-co-immobilization onto Ti implant could stimulate the response of pre-osteoblasts, with greater alkaline phosphatase activity and bone-like nodule formation ${ }^{43}$.

A normal range of $\mathrm{Ca} / \mathrm{P}$ will lead to optimal bone mineralization and bone formation ${ }^{17,22,44)}$. The $\mathrm{Ca} / \mathrm{P}$ of native bone hydroxyapatite (HA) is 1.67 in human, so most bone related bioactive materials aims at this criteria. An optimal range of $\mathrm{Ca} / \mathrm{P}$ was from 1.57 to 1.71 , which are closer to mature bone HA, could be beneficial to bone mineralization and formation. Furthermore at early calcification of nodules, 1.35 was good for bone mineralization ${ }^{45)}$. While in this study, $\mathrm{Ca} / \mathrm{P}$ was $1.1 \sim 1.3$ in experimental group and 1.3 1.6 in control group, and $\mathrm{Ca} / \mathrm{P}$ in experimental group was lower than that in control group. $\mathrm{Ca} / \mathrm{P}$ in control group is more benefical for bone mineralization and osteoblast differentiation at early stage.

In conclusion, hyperlipidemia hindered implant ossseointegration in rats at early stage after implantation. This inhibition might be modulated by overproduction of oxidative stress and low $\mathrm{Ca} / \mathrm{P}$, which further affected osteoblast differentiation, bone mineralization and formation.

\section{Acknowledgements}

This work was supported by the National Natural Science Foundation of China [grant numbers 81671025] and the Department of Science and Technology of ShandongProvince [grant number 2015GSF118186].

\section{Conflict of Interest}

There are no conflicts of interest in this study.

\section{References}

1. Guiglia R, Di Fede O, Lo Russo L, Sprini D, Rini GB and Campisi G. Osteoporosis, jawbones and periodontal disease. Med Oral Patol Oral Cir Bucal 18: e93-99, 2013

2. Keuroghlian A, Barroso ADV, Kirikian G, Bezouglaia O, Tintut Y, Tetradis S, Moy P, Pirih F and Aghaloo T. The effects of hyperlipidemia on implant osseointegration in the mouse femur. J Oral Implantol 41: E7-E11, 2015

3. Carroll MD, Fryar CD and Kit BK. Total and high-density lipoprotein cholesterol in adults: United States, 2011-2014. NCHS Data
Brief 1-8, 2015

4. Choukroun J, Khoury G, Khoury F, Russe P, Testori T, Komiyama Y, Sammartino G, Palacci P, Tunali M and Choukroun E. Two neglected biologic risk factors in bone grafting and implantology: high low-density lipoprotein cholesterol and low serum vitamin D. J Oral Implantol 40: 110-114, 2014

5. Pelton K, Krieder J, Joiner D, Freeman MR, Goldstein SA and Solomon KR. Hypercholesterolemia promotes an osteoporotic phenotype. Am J Pathol 181: 928-936, 2012

6. Huang X, Wang Z, Li D, Huang Z, Dong X, Li C and Lan J. Study of microRNAs targeted Dvl2 on the osteoblasts differentiation of rat BMSCs in hyperlipidemia environment. J Cell Physiol 2017

7. Pirih F, Lu J, Ye F, Bezouglaia O, Atti E, Ascenzi M-G, Tetradis S, Demer L, Aghaloo T and Tintut Y. Adverse effects of hyperlipidemia on bone regeneration and strength. J Bone Miner Res 27: 309318,2012

8. Lu C, Saless N, Wang X, Sinha A, Decker S, Kazakia G, Hou H, Williams B, Swartz HM, Hunt TK, Miclau T and Marcucio RS. The role of oxygen during fracture healing. Bone 52: 220-229, 2013

9. Wagegg M, Gaber T, Lohanatha FL, Hahne M, Strehl C, Fangradt M, Tran CL, Schoenbeck K, Hoff P, Ode A, Perka C, Duda GN and Buttgereit F. Hypoxia promotes osteogenesis but suppresses adipogenesis of human mesenchymal stromal cells in a hypoxia-inducible factor-1 dependent manner. PLoS One 7: 2012

10. Merceron C, Vinatier C, Portron S, Masson M, Amiaud J, Guigand L, Cherel Y, Weiss P and Guicheux J. Differential effects of hypoxia on osteochondrogenic potential of human adipose-derived stem cells. Am J Physiol Cell Physiol 298: C355-364, 2010

11. Holzwarth C, Vaegler M, Gieseke F, Pfister SM, Handgretinger R, Kerst G and Muller I. Low physiologic oxygen tensions reduce proliferation and differentiation of human multipotent mesenchymal stromal cells. BMC Cell Biol 11: 11, 2010

12. Brodeur MR, Brissette L, Falstrault L, Ouellet P and Moreau R. Influence of oxidized low-density lipoproteins (LDL) on the viability of osteoblastic cells. Free Radic Biol Med 44: 506-517, 2008

13. Ueno T, Ikeda T, Tsukimura N, Ishijima M, Minamikawa $H$, Sugita $Y$, Yamada M, Wakabayashi N and Ogawa T. Novel antioxidant capability of titanium induced by UV light treatment. Biomaterials 108: 177-186, 2016

14. Callaway DA and Jiang JX. Reactive oxygen species and oxidative stress in osteoclastogenesis, skeletal aging and bone diseases. J Bone Miner Metab 33: 359-370, 2015

15. Lee YH, Bhattarai G, Park IS, Kim GR, Kim GE, Lee MH and Yi $\mathrm{HK}$. Bone regeneration around $\mathrm{N}$-acetyl cysteine-loaded nanotube titanium dental implant in rat mandible. Biomaterials 34: 1019910208, 2013

16. Olgun $\mathrm{O}$ and Aygun A. Nutritional factors affecting the breaking strength of bone in laying hens. World Poultry Sci 72: 821-832, 2016

17. Acar DB, Kavuncuoglu S, Cetinkaya M, Petmezci E, Dursun M, Korkmaz O and Altuncu EK. Assessment of the place of tubular reabsorption of phosphorus in the diagnosis of osteopenia of prematurity. Turk Pediatri Ars 50: 45-50, 2015

18. Mohammadi H, Hafezi M, Nezafati N, Heasarki S, Nadernezhad A, Ghazanfari SMH and Sepantafar M. Bioinorganics in bioactive calcium silicate ceramics for bone tissue repair: bioactivity and biological properties. J Ceram Sci Technol 5: 1-12, 2014

19. Habibovic P and Barralet JE. Bioinorganics and biomaterials: bone repair. Acta Biomater 7: 3013-3026, 2011 
20. Gupta $\mathrm{S}$ and Reviakine I. Platelet activation profiles on TiO2: effect of $\mathrm{Ca} 2+$ binding to the surface. Biointerphases 7: 28, 2012

21. Marie PJ. The calcium-sensing receptor in bone cells: a potential therapeutic target in osteoporosis. Bone 46: 571-576, 2010

22. Christmann V, Gradussen CJ, Kornmann MN, Roeleveld N, van Goudoever JB and van Heijst AF. Changes in biochemical parameters of the calcium-phosphorus homeostasis in relation to nutritional Intake in very-low-birth-weight infants. Nutrients 8: 2016

23. Shapiro R and Heaney RP. Co-dependence of calcium and phosphorus for growth and bone development under conditions of varying deficiency. Bone 32: 532-540, 2003

24. Coats AM, Zioupos P and Aspden RM. Material properties of subchondral bone from patients with osteoporosis or osteoarthritis by microindentation testing and electron probe microanalysis. Calcif Tissue Int 73: 66-71, 2003

25. Kourkoumelis N, Balatsoukas I and Tzaphlidou M. Ca/P concentration ratio at different sites of normal and osteoporotic rabbit bones evaluated by Auger and energy dispersive X-ray spectroscopy. J Biol Phys 38: 279-291, 2012

26. Palma-Carrio C, Maestre-Ferrin L, Penarrocha-Oltra D, Penarrocha-Diago MA and Penarrocha-Diago M. Risk factors associated with early failure of dental implants. A literature review. Med Oral Patol Oral Cir Bucal 16: e514-517, 2011

27. Esposito M, Hirsch JM, Lekholm U and Thomsen P. Biological factors contributing to failures of osseointegrated oral implants. (II). Etiopathogenesis. Eur J Oral Sci 106: 721-764, 1998

28. Sage AP, Lu J, Atti E, Tetradis S, Ascenzi MG, Adams DJ, Demer LL and Tintut Y. Hyperlipidemia induces resistance to PTH bone anabolism in mice via oxidized lipids. J Bone Miner Res 26: 11971206, 2011

29. Xin L, Jamie G, Jinxiu L, Sidney I, Ivo K, David R, Demer LL and Yin $\mathrm{T}$. Roles of parathyroid hormone (PTH) receptor and reactive oxygen species in hyperlipidemia-induced PTH resistance in preosteoblasts. J Cell Biochem 115: 179-188, 2013

30. Marco F, Milena F, Gianluca G and Vittoria O. Peri-implant osteogenesis in health and osteoporosis. Micron 36: 630-644, 2005

31. Ionova-Martin SS, Do SH, Barth HD, Szadkowska M, Porter AE, Ager JWR, Ager JW, Jr., Alliston T, Vaisse C and Ritchie RO. Reduced size-independent mechanical properties of cortical bone in high-fat diet-induced obesity. Bone 46: 217-225, 2010

32. Laurila A, Cole SP, Merat S, Obonyo M, Palinski W, Fierer J and Witztum JL. High-fat, high-cholesterol diet increases the incidence of gastritis in LDL receptor-negative mice. Arterioscler Thromb Vasc Biol 21: 991-996, 2001

33. Dong X, Wang Z, Wang H and Lan J. The research of dishevelled-2 in dental implant osseointegration of hyperlipidemic rats. Int J Oral Maxillofac Implants 33: 351-356, 2018

34. Maziere C, Salle V, Gomila C and Maziere JC. Oxidized low density lipoprotein enhanced RANKL expression in human osteoblast-like cells. Involvement of ERK, NFkappaB and NFAT. Biochim Biophys Acta 1832: 1756-1764, 2013

35. Almeida M, Ambrogini E, Han L, Manolagas SC and Jilka RL. Increased lipid oxidation causes oxidative stress, increased peroxisome proliferator-activated receptor-gamma expression, and diminished pro-osteogenic Wnt signaling in the skeleton. J Biol Chem 284: 27438-27448, 2009

36. Wu S and De Luca F. Role of cholesterol in the regulation of growth plate chondrogenesis and longitudinal bone growth. J Biol Chem 279: 4642-4647, 2004

37. Koerdt S, Siebers J, Bloch W, Ristow O, Kuebler AC and Reuther T. Role of oxidative and nitrosative stress in autogenous bone grafts to the mandible using guided bone regeneration and a deproteinized bovine bone material. J Cranio Maxill Surg 42: 560-567, 2014

38. Anitua E, Prado R, Orive G and Tejero R. Effects of calcium-modified titanium implant surfaces on platelet activation, clot formation, and osseointegration. J Biomed Mater Res A 103: 969-980, 2015

39. Welldon KJ, Findlay DM, Evdokiou A, Ormsby RT and Atkins GJ. Calcium induces pro-anabolic effects on human primary osteoblasts associated with acquisition of mature osteocyte markers. Mol Cell Endocrinol 376: 85-92, 2013

40. Barradas AM, Fernandes HA, Groen N, Chai YC, Schrooten J, van de Peppel J, van Leeuwen JP, van Blitterswijk CA and de Boer J. A calcium-induced signaling cascade leading to osteogenic differentiation of human bone marrow-derived mesenchymal stromal cells. Biomaterials 33: 3205-3215, 2012

41. Khoshniat S, Bourgine A, Julien M, Petit M, Pilet P, Rouillon T, Masson M, Gatius M, Weiss P, Guicheux J and Beck L. Phosphate-dependent stimulation of MGP and OPN expression in osteoblasts via the ERK1/2 pathway is modulated by calcium. Bone 48 : 894-902, 2011

42. Anitua E, Pinas L, Murias A, Prado R and Tejero R. Effects of calcium ions on titanium surfaces for bone regeneration. Colloids Surf B Biointerfaces 130: 173-181, 2015

43. Sunarso, Toita R, Tsuru K and Ishikawa K. Immobilization of calcium and phosphate ions improves the osteoconductivity of titanium implants. Mater Sci Eng C Mater Biol Appl 68: 291-298, 2016

44. De Curtis $M$ and Rigo J. Nutrition and kidney in preterm infant. J Matern Fetal Neonatal Med 25 Suppl 1: 55-59, 2012

45. Bonucci E. Bone mineralization. Front Biosci (Landmark Ed) 17: 100-128, 2012 